\title{
KẾT QUẢ KHẢO SÁT BƯớC ĐẦU VỀ TÌNH HÌNH VIẾT SAI, VIÊTT NHẦM CHỬ HÁN CỦA SINH VIÊN VIỆT NAM
}

\author{
Nguyễn Đình Hiền*
}

Khoa Ngôn ngũ và Văn hóa Trung Quốc, Truờng Đại học Ngoại ngũu, ĐHQGHN, Phạm Văn Đồng, Cầu Giấy, Hà Nội, Việt Nam

Nhận bài ngày 06 tháng 12 năm 2016

Chỉnh sửa ngày 21 tháng 12 năm 2016; Chấp nhận đăng ngày 06 tháng 01 năm 2017

Tóm tắt: Chữ Hán là một trong những khó khăn lớn nhất của sinh viên Việt Nam khi học tiếng Hán. Hiện tượng viết sai, viết nhầm diễn ra rất phổ biến, song những thành tựu nghiên cứu về lĩnh vực này còn tương đối hạn chế. Bài viết tiến hành khảo sát những chữ Hán viết sai, viết nhầm của sinh viên Việt Nam dựa trên việc phân tích ngữ liệu 150 bài thi tốt nghiệp môn viết của sinh viên khóa QH 2011, Khoa Ngôn ngữ và Văn hóa Trung Quốc, Trường Đại học Ngoại ngữ, Đại học Quốc gia Hà Nội (ĐHQGHN). Tiếp đó, bài viết đi sâu vào phân loại các chữ viết sai, viết nhầm, trên cơ sở đó đưa ra những kiến nghị đối với việc dạy và học chữ Hán cho sinh viên chuyên ngành tiếng Trung Quốc của Việt Nam.

Tù khóa: văn tự, chữ Hán, chữ viết sai, chữ viết nhầm, nét, bộ, chữ

\section{1. Đặt vấn đề̀ $(1)$}

Văn tự là hệ thống các ký hiệu ghi chép ngôn ngữ của các dân tộc, văn tự trên thế giới có thể chia thành hai loại chính, văn tự biểu âm và văn tự biểu ý. Sự khác biệt cơ bản của hai loại văn tự này là văn tự biểu âm chỉ dùng một lượng có hạn các ký hiệu (ký hiệu nguyên âm, phụ âm, thanh điệu) để ghi chép ngữ âm của một ngôn ngũ̃, trong khi đó văn tự biểu ý phải dùng một lượng tương đối lớn các ký hiệu để biểu thị ý nghĩa của các ngữ tố hay từ của ngôn ngữ đó.

Chữ Hán cổ là loại văn tự biểu ý, mặc dù hiện nay đại đa số các học giả đều đồng ý rằng chữ Hán hiện đại là loại văn tự ngữ tố biểu thị ý âm (意音语素文字), song tác dụng biểu âm của chữ Hán là rất hạn chế. Điều này hoàn toàn khác với chữ Quốc ngữ, loại chữ

* ĐT.: 84-904244708, Email: hienac@yahoo.com

${ }^{1}$ Nghiên cứu này được thực hiện với sự tham gia tài trợ của Quỹ Sunwah trong đề tài mã số US.16.03 biểu âm của Việt Nam. Sinh viên Việt Nam rất bỡ ngỡ khi bắt đầu học viết chữ Hán, việc viết chữ được ví như là vẽ chữ. Hơn nữa, do chữ Hán không phải là loại văn tự biểu âm nên người học phải nắm một lượng lớn số chữ mới có thể sử dụng được. Chính vì vậy, chữ Hán luôn được coi là một trong những khó khăn lớn nhất của sinh viên Việt Nam trong khi học tiếng Hán. Chưa bàn đến chữ viết có đẹp hay không, riêng việc viết đúng chữ Hán đã là một khó khăn rất lớn, hiện tượng viết sai, viết nhầm diễn ra rất phổ biến. Không chỉ vậy, kết quả khảo sát cho thấy có nhiều chữ sinh viên không viết được phải bỏ trống hoặc chỉ viết phiên âm.

Bài viết lấy chữ Hán của sinh viên năm thứ tư Khoa Ngôn ngữ và Văn hóa Trung Quốc, Trường Đại học Ngoại ngữ, ĐHQGHN làm đối tượng nghiên cứu. Cụ thể chúng tôi sử dụng 150 bài thi tốt nghiệp môn viết của sinh viên khóa QH 2011 làm ngữ liệu nghiên cứu. 
Sau khi khảo sát và phân tích, chúng tôi dựa trên những số liệu thống kê để trả lời các câu hỏi như: trung bình mỗi bài viết của sinh viên ngành tiếng Trung lúc ra trường có bao nhiêu chữ viết sai, bao nhiêu chữ viết nhầm? Số lượt là bao nhiêu? Những chữ sinh viên thường hay viết sai, viết nhầm là những chữ nào?

Sau khi thống kê, phân tích, chúng tôi mạnh dạn đưa ra những kiến nghị đối với người học để giúp họ nâng cao khả năng viết chữ Hán, tránh mắc phải những lỗi viết sai, viết nhầm đáng tiếc. Chúng tôi cũng đưa ra những lời khuyên đối với người dạy, người biên soạn chương trình, giáo trình để giúp họ hoàn thành tốt công việc của mình.

\section{Các bước tiến hành khảo sát}

Bài viết sử dụng bài thi tốt nghiệp môn viết của sinh viên khóa QH 2011 làm ngữ liệu nghiên cứu. Khóa QH 2011 tốt nghiệp năm 2015, theo quy định trước khi ra trường, các bạn sinh viên nếu không làm khóa luận thì phải thi các môn nghe, nói, đọc, viết và một môn lý thuyết. Bài thi môn viết được đánh số phách từ V1 đến V151, song không có số phách V76, như vậy tổng cộng có tất cả 150 bài. Đề thi gồm 2 câu, đều dưới hình thức tự luận, thời gian làm bài 60 phút. Câu 1 viết đoạn văn khoảng 150 chũ̃ thuật lại sự việc xảy ra của một ngày khi em dậy muộn. Câu 2 viết bài văn nghị luận 450 chữ thể hiện quan điểm của em đối với câu hỏi "người Hà Nội có hạnh phúc không?"

Việc xử lý ngữ liệu được tiến hành với các bước: 1) Đọc kỹ, tìm ra và đánh dấu tất cả những chữ viết có vấn đề ở 150 bài thi. Những chữ viết có vấn đề bao gồm những chữ viết sai (viết chữ Hán A thành một chữ không có trong hệ thống chữ Hán), những chữ viết nhầm (vốn định viết chữ $A$ nhưng viết nhầm thành chữ $B$ ), viết phiên âm, không viết được nên bỏ trống;
2) Nhập ngữ liệu vào excel và phân tích chúng theo nét bút (có thể sai hoặc nhầm do thiếu, thừa nét, viết sai loại nét bút, độ dài ngắn của nét không đúng), bộ (thừa thiếu bộ, vị trí các bộ, sai bộ ...), chữ (sai hoặc nhầm do ảnh hưởng của âm, hình hay ý);

3) Tiến hành phân loại các chữ viết sai, viết nhầm;

4) Dựa trên kết quả khảo sát, bài viết đưa ra những kiến nghị đối với việc dạy và học chữ Hán.

\section{Kết quả khảo sát}

\subsection{Số liệu chung}

Kết quả khảo sát bước đầu cho thấy trong 150 bài viết của sinh viên có 1147 chữ viết có vấn đề, trong đó: 502 chữ viết nhầm, 460 chữ viết sai, 166 chữ viết phiên âm, 19 chữ không viết. Đối với 19 chữ không viết, chúng tôi dựa vào ngữ cảnh xác định được 15 chữ, có 4 chữ chúng tôi không xác định được. Kết quả cụ thể xin xem bảng dưới đây:

\begin{tabular}{|c|c|c|c|c|c|}
\hline $\begin{array}{c}\text { Số/ lượt } \\
\text { chữ }\end{array}$ & $\begin{array}{c}\text { Không } \\
\text { viết }\end{array}$ & $\begin{array}{c}\text { Viết } \\
\text { phiên âm }\end{array}$ & $\begin{array}{c}\text { Viết } \\
\text { nhầm }\end{array}$ & Viết sai & Tổng \\
\hline Số chữ & $\begin{array}{c}19 \\
(1,66 \%)\end{array}$ & $\begin{array}{c}166 \\
(14,47 \%)\end{array}$ & $\begin{array}{c}502 \\
(43,77 \%)\end{array}$ & $\begin{array}{c}460 \\
(40,1 \%)\end{array}$ & $\begin{array}{c}1147 \\
\text { chữ }\end{array}$ \\
\hline $\begin{array}{c}\text { Lượt } \\
\text { chữ }\end{array}$ & $\begin{array}{c}20 \\
(0,64 \%)\end{array}$ & $\begin{array}{c}230 \\
(7,32 \%)\end{array}$ & $\begin{array}{c}1242 \\
(39,54 \%)\end{array}$ & $\begin{array}{c}1649 \\
(52,5 \%)\end{array}$ & $\begin{array}{c}3141 \\
\text { lượt }\end{array}$ \\
\hline
\end{tabular}

Có trường hợp cùng một chữ nhưng ở bài thi này thì viết nhầm ở bài thi khác thì viết sai, hay ở bài thi này thì viết sai ở bài thi khác thì viết phiên âm, ... Con số 1147 chữ ở bảng trên là tính cả các trường hợp trùng nhau đó, nếu loại trừ những trường hợp trùng nhau thì có tổng cộng 846 chữ có vấn đề. Bài viết phân loại các lỗi sai, từ đó tìm ra giải pháp để khắc phục tình trạng viết sai viết nhầm nên chúng tôi lấy con số 1147 chữ để phân tích. Như vậy, trong 150 bài thi của sinh viên thì có 1147 chữ có vấn đề, trung bình mỗi bài thi có 7,65 chữ có vấn đề. Con số sẽ lớn hơn nhiều nếu nhìn vào số lượt chữ có vấn 
đề. Tổng cộng có 3141 lượt chữ có vấn đề, trung bình mỗi bài có 20,94 lượt chữ.

“已，觉，学，河，里，展，幸，真， 城, 试, 题, 污” là những chữ có số bài viết phạm lỗi nhiều nhất, số liệu thống kê cụ thể như bảng dưới đây: viết được): 部 (一部电影), 精 (精神), 规 (规 模), 游 (旅游), 展 (发展), 顿 (一顿饭), 健 ( 健康), 染 (污染), 悔 (后悔), 例 (例外), 拾 ( 收拾), 考 (高考), 怜 (可怜), 坚 (坚决), 污 ( 污染). Đây đều là những chữ cơ bản, thường dùng của tiếng Hán. Điều này phần nào phản

\begin{tabular}{|c|c|c|c|c|c|c|c|c|c|}
\hline Chữ & 已 & 觉 & 学 & 河 & 里 & 展 & 幸 & 真 & 城试题污 \\
\hline Số bài & 60 & 52 & 31 & 30 & 26 & 23 & 22 & 21 & 20 \\
\hline Tỉ lệ & $40,00 \%$ & $34,67 \%$ & $20,67 \%$ & $20,00 \%$ & $17,33 \%$ & $15,33 \%$ & $14,67 \%$ & $14,00 \%$ & $13,33 \%$ \\
\hline $\begin{array}{c}\text { Thứ } \\
\text { tự }\end{array}$ & 1 & 2 & 3 & 4 & 5 & 6 & 7 & 8 & 9 \\
\hline
\end{tabular}

Nhìn vào bảng trên đây, chúng ta thấy chữ “已” có số lượng bài viết có vấn đề lớn nhất, có tất cả 60 bài, chiếm $40 \%$ tổng số bài thi, tiếp đến là các chữ “觉” 52 bài, chữ “学” 31 bài, chữ “ 河” 30 bài, chữ “里” 26 bài..., bốn chữ “城, 试, 题, 污” đều có số bài giống nhau là 20 bài.

Nếu xét về số lượt lỗi sai thì “河, 觉, 学, 已, 幸, 那, 越, 城, 展, 试” là 10 chữ có lượt lỗi sai nhiều nhất, trong đó “河” 109 lượt sai, “学” 100 lượt sai, số liệu thống kê xin xem bảng dưới đây:

\begin{tabular}{|c|c|c|c|c|c|c|c|c|c|c|}
\hline Chữ & 河 & 觉 & 学 & 已 & 幸 & 那 & 越 & 城 & 展 & 试 \\
\hline Số lượt & 109 & 100 & 82 & 79 & 45 & 40 & 39 & 35 & 34 & 33 \\
\hline Thứ tự & 1 & 2 & 3 & 4 & 5 & 6 & 7 & 8 & 9 & 10 \\
\hline
\end{tabular}

ánh trình độ viết chữ Hán của sinh viên khi ra trường còn khá hạn chế.

Số chữ viết phiên âm là 166 chữ, số lượt là 230. Song điều đáng chú ý là trong số này có 26 chữ viết sai phiên âm, với số lượt là 33 . Cá biệt có một vài phiên âm không điền thanh điệu, ví dụ “耽” trong “耽误” chỉ phiên âm là “dan", trong khi đó phiên âm đúng là "dān"; “ 吸” trong “吸引” chỉ phiên âm là “xi”, trong khi đó phiên âm đúng là "x $\overrightarrow{1}$ ”. Kết quả này cho thấy không chỉ khả năng viết chữ của sinh viên có hạn mà khả năng nắm âm đọc của chữ cũng còn nhiều vấn đề. Bảng dưới đây là một số ví dụ cụ thể:

\begin{tabular}{|c|c|c|c|c|c|c|c|c|c|c|c|c|}
\hline Chữ & 灾 & 颠 & 秀 & 责 & 健 & 架 & 害 & 便 & 村 & 虽 & 集 & 符 \\
\hline Phiên âm & zāi & diān & xiù & zé & jiàn & jià & hài & biàn & cūn & sūi & jí & fú \\
\hline $\begin{array}{c}\text { Phiên âm } \\
\text { sai }\end{array}$ & cái & diàn & xiū & zhé & jiān & jiā & hāi & piàn & cùn & suì & jī & fù \\
\hline Từ & $\begin{array}{c}\text { 灾 } \\
\text { 难 }\end{array}$ & $\begin{array}{c}\text { 颠 } \\
\text { 倒 }\end{array}$ & $\begin{array}{c}\text { 优 } \\
\text { 秀 }\end{array}$ & $\begin{array}{c}\text { 指 } \\
\text { 责 }\end{array}$ & $\begin{array}{c}\text { 健 } \\
\text { 康 }\end{array}$ & $\begin{array}{c}\text { 打 } \\
\text { 架 }\end{array}$ & $\begin{array}{c}\text { 害 } \\
\text { 羞 }\end{array}$ & $\begin{array}{c}\text { 方 } \\
\text { 便 }\end{array}$ & $\begin{array}{c}\text { 农 } \\
\text { 村 }\end{array}$ & $\begin{array}{c}\text { 虽 } \\
\text { 然 }\end{array}$ & $\begin{array}{c}\text { 集 } \\
\text { 中 }\end{array}$ & $\begin{array}{c}\text { 符 } \\
\text { 合 }\end{array}$ \\
\hline
\end{tabular}

\subsection{Các chũ không viết và các chũ chỉ viết} phiên âm

Như trên đã trình bày, có tổng cộng 19 chữ sinh viên bỏ trống trong bài, trong đó có 4 chữ chúng tôi không xác định được là những chữ gì, 15 chữ không viết được còn lại bao gồm (trong ngoặc là từ ngữ chứa chữ không

\subsection{Các chũ viết nhầm}

Có tổng số 1242 lượt chữ viết nhầm, chiếm $39,54 \%$ tổng lượt chữ có vấn đề, số lượng này là tương đối lớn và chỉ đứng sau số lượt chữ viết sai. Đối với các chữ viết nhầm chúng tôi chia thành: 1. Chữ viết nhầm do ảnh hưởng của âm đọc; 2 . Chữ viết nhầm do ảnh hưởng của hình thể; 3 . Chữ 
viết nhầm do ảnh hưởng của cả âm đọc và hình thể; 4. Chữ viết nhầm do những nguyên nhân khác. Bảng dưới đây là các con số thống kê:

\begin{tabular}{|c|c|c|c|c|c|}
\hline $\begin{array}{c}\text { Số } \\
\text { lượt/ } \\
\text { tỉ lệ }\end{array}$ & $\begin{array}{c}\text { Ảnh } \\
\text { hưởng } \\
\text { của âm } \\
\text { đọc }\end{array}$ & $\begin{array}{c}\text { Ảnh } \\
\text { hưởng } \\
\text { của hình } \\
\text { thể }\end{array}$ & $\begin{array}{c}\text { Ảnh } \\
\text { hưởng } \\
\text { của } \\
\text { cả âm và } \\
\text { hình }\end{array}$ & $\begin{array}{c}\text { Nguyên } \\
\text { nhân } \\
\text { khác }\end{array}$ & Tổng \\
\hline Số lượt & 213 & 402 & 578 & 49 & 1242 \\
\hline Tỉ lệ & $17,15 \%$ & $32,37 \%$ & $46,54 \%$ & $3,95 \%$ & $100,00 \%$ \\
\hline
\end{tabular}

Kết quả thống kê ở bảng trên đây cho thấy số lượt chữ nhầm nhiều nhất là do ảnh hưởng của cả âm đọc và hình thể của chữ, có tổng cộng 578 lượt nhầm, chiếm 46,54\% tổng số lượt nhầm; xếp thứ hai là lượt chữ nhầm do ảnh hưởng của hình thể, 402 lượt, chiếm 32,37\%; tiếp đến là lượt chữ nhầm do ảnh hưởng của âm đọc, 213 lượt, chiếm 17,15\%; cuối cùng là những chữ nhầm do những nguyên nhân khác, 49 lượt, chiếm 3,95\%. Dưới đây chúng tôi đi sâu vào phân tích từng loại.

Chữ viết nhầm do ảnh hưởng của âm đọc là hiện tượng chữ $\mathrm{A}$ do có âm đọc giống (đồng âm) hoặc gần giống (cận âm) với chữ $\mathrm{B}$ mà bị viết nhầm thành chũ̃ $\mathrm{B}$. Loại chữ này có số lượt nhầm là 213 lượt, chiếm 17,15\% tổng số lượt nhầm. Nếu tiếp tục đi sâu vào phân tích loại này, thì có 125 lượt chữ nhầm do đồng âm, 88 lượt chữ nhầm do cận âm; trong 88 lượt chữ nhầm do cận âm thì có đến 55 lượt nhầm do hai chữ có cả thanh mẫu và vận mẫu giống nhau, chỉ có thanh điệu khác nhau, chỉ có 33 lượt chữ nhầm do có sự khác nhau về thanh mẫu hay vận mẫu. Bảng dưới đây là một số ví dụ về chữ nhầm do đồng âm:

\begin{tabular}{|c|c|c|c|c|c|c|c|c|c|c|c|c|}
\hline $\begin{array}{c}\text { Chữ } \\
\text { đúng }\end{array}$ & 扮 & 毕 & 承 & 触 & 答 & 待 & 锻 & 工 & 观 & 绝 & 释 & 误 \\
\hline $\begin{array}{c}\text { Chữ } \\
\text { nhầm }\end{array}$ & 办 & 必 & 成 & 处 & 达 & 代 & 段 & 公 & 关 & 决 & 事 & 物 \\
\hline Từ & $\begin{array}{c}\text { 打 } \\
\text { 毕 }\end{array}$ & 承 & 接 & 回 & 待 & 锻 & 工 & 观 & 绝 & 解 & 错 \\
& 担 & 触 & 答 & 遇 & 炼 & 程 & 点 & 望 & 释 & 误 \\
\hline
\end{tabular}

Bảng dưới đây là một số ví dụ về chữ nhầm do cận âm:

\begin{tabular}{|c|c|c|c|c|c|c|c|c|c|c|c|c|}
\hline $\begin{array}{c}\text { Chữ } \\
\text { đúng }\end{array}$ & 按 & 便 & 标 & 符 & 害 & 技 & 即 & 举 & 闹 & 奇 & 幸 & 纸 \\
\hline $\begin{array}{c}\text { Chữ } \\
\text { nhầm }\end{array}$ & 暗 & 边 & 表 & 复 & 开 & 机 & 既 & 取 & 脑 & 极 & 星 & 志 \\
\hline Từ & $\begin{array}{c}\text { 按 } \\
\text { 随 }\end{array}$ & 标 & 符 & 害 & 技 & 即 & 举 & 闹 & 好 & 幸 & 报 \\
倠 & 合 & 怕 & 能 & 使 & 止 & 钟 & 奇 & 运 & 纸 \\
\hline
\end{tabular}

Chữ viết nhầm do ảnh hưởng của hình thể là hiện tượng chữ $\mathrm{A}$ do có hình dạng gần giống với chữ $\mathrm{B}$ mà bị viết nhầm thành chữ B. Loại chữ này có số lượt nhầm là 402 lượt, chiếm 32,37\% tổng số lượt nhầm. Bảng dưới đây là một số ví dụ:

\begin{tabular}{|c|c|c|c|c|c|c|c|c|c|c|c|c|}
\hline $\begin{array}{c}\text { Chữ } \\
\text { đúng }\end{array}$ & 外 & 己 & 午 & 多 & 村 & 街 & 民 & 市 & 末 & 统 & 铭 & 厂 \\
\hline $\begin{array}{c}\text { Chữ } \\
\text { nhầm }\end{array}$ & 处 & 巳 & 牛 & 勿 & 材 & 衡 & 氏 & 布 & 未 & 流 & 铅 & 广 \\
\hline Từ & $\begin{array}{c}\text { 例 } \\
\text { 外 }\end{array}$ & 自 & $\begin{array}{c}\text { 下 } \\
\text { 多 }\end{array}$ & 农 & 古 & 人 城 & 期 & 统 & 铭 & 工 \\
街 & 民 & 市 & 末 & 记 & 厂 \\
\hline
\end{tabular}

Chữ viết nhầm do ảnh hưởng của cả âm đọc và hình thể là hiện tượng chữ $\mathrm{A}$ do có âm đọc giống hoặc gần giống, có hình dạng gần giống với chữ $\mathrm{B}$ mà bị viết nhầm thành chữ $\mathrm{B}$. Loại chữ này có số lượt nhầm nhiều nhất trong các loại, 578 lượt, chiếm 46,54\% tổng số lượt nhầm. Điều này là hoàn toàn dễ hiểu, bởi những chữ giống hoặc gần giống nhau về cả hai mặt âm đọc và hình thể thì sẽ dễ gây nhầm lẫn hơn các chữ chỉ giống nhau về một mặt là âm đọc hoặc hình thể. Bảng dưới đây là một số ví dụ:

\begin{tabular}{|c|c|c|c|c|c|c|c|c|c|c|c|c|}
\hline $\begin{array}{l}\text { Chữ } \\
\text { đúng }\end{array}$ & 精 & 曾 & 历 & 峻 & 境车 & 转 & 汽 & 荒 & 霉 & 亲 & 炼 & 健 \\
\hline $\begin{array}{l}\text { Chữ } \\
\text { nhầm }\end{array}$ & 情 & 增 & 厉 & 俊 & 竟 & 传 & 气| & 慌 & 梅 & 辛 & 练 & 建 \\
\hline Từ & 申 & \begin{tabular}{|l|} 
曾 \\
经 \\
\end{tabular} & \begin{tabular}{|l|} 
经 \\
历
\end{tabular} & \begin{tabular}{|l|} 
严 \\
峻
\end{tabular} & \begin{tabular}{l|l} 
环 & 车 \\
境 & 目
\end{tabular} & 转 & \begin{tabular}{l|l} 
汽 \\
车 \\
\end{tabular} & 荒 & 倒 & \begin{tabular}{l|} 
亲 \\
爱
\end{tabular} & 锻 & $\begin{array}{l}\text { 健 } \\
\text { 康 }\end{array}$ \\
\hline
\end{tabular}

Những chữ nhầm do những nguyên nhân khác có 49 lượt, chiếm 3,95\% tổng lượt chữ nhầm. Những nguyên nhân khác ở đây có thể là: 1 . Do không nắm chắc cách viết của các chữ trong từ nên viết nhầm chữ trước với chữ sau, 
ví dụ: bài 32 từ “污染” bị viết thành “染污”, bài 116 từ “事故” bị viết thành “故事”, bài 131 từ “宿舍” bị viết thành “舍宿”, bài 149 từ “ 影响” bị viết thành “响影”, bài 75 từ “简单” thì chữ “简” viết phiên âm là "jiăn” còn chữ “ 单” viết nhầm thành chữ “简”; 2 . Nhầm do ảnh hưởng của chữ trước hoặc chữ sau: bài 20 từ “ 运动” viết thành “动动”, bài 23 từ “居民” viết thành “居居”; 3. Nhầm sang một chữ khác có quan hệ mật thiết với chữ trước hoặc sau, ví dụ bài 77 từ “知识” viết thành “知认” rất có thể là vì “认” và “识” thường đi với nhau trong từ “ 认识”, bài 89 từ “优势” viết thành “优趋” rất có thể là vì “趋” và “势” thường đi với nhau trong từ “趋势”, bài 103 từ “警察” viết thành “警观” rất có thể là vì “观” và “察” thường đi với nhau trong từ “观察”. Nhìn chung các chữ nhầm do những nguyên nhân khác có số lượng không lớn và không thành hệ thống, vì vậy không phải trọng tâm mà bài viết bàn tới.

\subsection{Các chũ viết sai}

Như trên đã thống kê, trong ngũ̃ liệu nghiên cứu, chúng tôi tìm được 460 chữ viết sai, chiếm 40,1\% tổng số chữ có vấn đề, con số này đứng thứ hai sau chữ viết nhầm. Song nếu xét về số lượt thì chữ viết sai lại đứng đầu với 1649 lượt, chiếm 52,5\% tổng số lượt các chữ có vấn đề.

Mặc dù xác định được các chữ viết sai, song để phân loại và chỉ ra lỗi sai ở từng chữ cụ thể là điều không đơn giản. Sở dĩ như vậy là vì đại đa số sinh viên viết ngoáy, chữ viết xấu, nhiều chữ bị dập xóa, nhiều chữ tương đối mờ. Mặt khác, các chữ viết sai không có trong phông chữ Hán, chúng tôi chỉ có thể xử lý bằng cách chụp ảnh và cắt trực tiếp các chữ sai ở bài viết của sinh viên để đưa vào sử dụng trong bài. Dưới đây chúng tôi bước đầu phân tích các chữ viết sai của sinh viên dựa trên các nét bút và các bộ cấu tạo nên chữ.

Nếu căn cứ vào các bộ cấu tạo nên chữ, có thể chia những chữ viết sai thành các loại như: 1 . Chữ sai do thừa bộ; 2 . Chữ sai do thiếu bộ; 3. Chữ sai do nhầm bộ (nhầm bộ này với bộ khác); 4. Chữ sai do vị trí của bộ hoặc vị trí giữa các bộ không chính xác (dưới đây gọi tắt là chữ sai do vị trí bộ); 5 . Chữ sai do viết sai bộ. Bảng dưới đây là một số ví dụ cụ thể, trong đó hình ảnh là chữ sai, chữ nhỏ bên cạnh là chữ đúng:

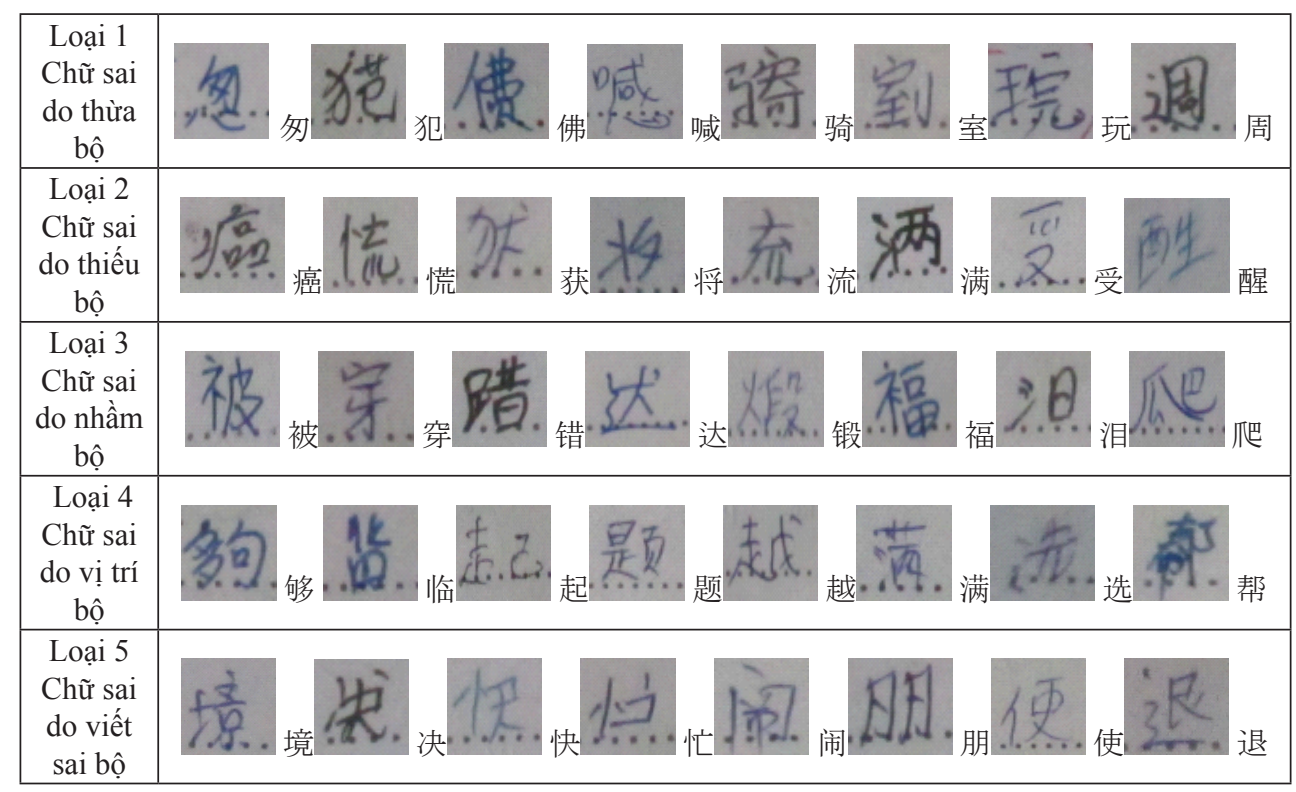


Ngoài năm loại chữ sai trên đây, nếu căn cứ vào các bộ cấu tạo nên chữ, chúng tôi cho rằng còn một loại chữ sai tổng hợp từ 5 loại trên, dưới đây chúng tôi lấy một số ví dụ để phân tích:

\begin{tabular}{|c|c|c|}
\hline Chữ sai & $\begin{array}{l}\text { Chữ } \\
\text { đúng }\end{array}$ & Phân tích \\
\hline & 获 & $\begin{array}{l}\text { Thiếu bộ thảo đầu “+””, nhưng lại } \\
\text { thừa bộ bốn chấm hỏa “....”,, vì vậy } \\
\text { là tông hợp của loại } 1 \text { và loại } 2 \text {. }\end{array}$ \\
\hline & 突 & $\begin{array}{l}\text { Thừa bộ bốn chấm hỏa “....”, nhầm } \\
\text { bộ huyệt “穴” thành bộ miên “, ", } \\
\text {, vì vậy là tổng hợp của loại } 1 \text { và } \\
\text { loại } 3 \text {. }\end{array}$ \\
\hline & 睡 & $\begin{array}{c}\text { Thừa bộ thảo đầu “+”, viết sai bộ } \\
\text { thùy “垂”, vì vậy là tồng hợp của } \\
\text { loại } 1 \text { và loại } 5 \text {. }\end{array}$ \\
\hline & 裤 & $\begin{array}{l}\text { Nhầm bộ y “衣” thành bộ thị “ネ” } \\
\text {, thiếu bộ quảng “广””, vì vậy là } \\
\text { tổng hợp của loại } 2 \text { và loại } 3 \text {. }\end{array}$ \\
\hline & 观 & $\begin{array}{l}\text { Nhầm bộ hựu “丈” thành bộ bán } \\
\text { văn “文”, sai vị trí của các bộ, vì } \\
\text { vậy là tổng hợp của loại } 3 \text { và loại } 4 \text {. }\end{array}$ \\
\hline & 醒 & $\begin{array}{l}\text { Sai vị trí của các bộ, viết sai bộ } \\
\text { dậu (西), vì vậy là tồng hợp của } \\
\text { loại } 4 \text { và loại } 5 \text {. }\end{array}$ \\
\hline
\end{tabular}

Nếu căn cứ vào các nét bút cấu tạo nên chữ, có thể chia những chữ viết sai thành các loại như: 1 . Chữ sai do thừa nét; 2 . Chữ sai do thiếu nét; 3 . Chữ sai do nhầm nét (nhầm nét này với nét khác); 4. Chữ sai do nét bút có độ dài ngắn không chính xác (dưới đây gọi tắt là chữ sai do độ dài nét). Bảng dưới đây là một số ví dụ cụ thể, trong đó hình ảnh là chữ sai, chữ nhỏ bên cạnh là chữ đúng:

\section{Kiến nghị đối với việc dạy và học chữ Hán}

\section{1. Đối với việc dạy chũ Hán}

Chữ Hán không thuộc hệ thống văn tự biểu âm mà thuộc hệ thống văn tự biểu ý. Mặc dù trong chữ Hán hiện đại ngày nay, chữ hình thanh chiếm một lượng lớn (trong Thuyết văn giải tư chữ hình thanh đã chiếm $82 \%$ tổng số chữ, 张 静贤, 2004: 21), song tác dụng biểu âm của thanh phù nói riêng và của chữ Hán nói chung là rất hạn chế. Để sử dụng được, người học phải nhớ và viết được một lượng lớn chữ Hán. Theo 张 静贤 (2004: 15), Tân Hoa tụ điển do Thương vụ ấn thư quán xuất bản năm 1998 gồm tổng cộng hơn 10 nghìn chữ, Bảng chũ thường dùng của tiếng Hán hiện đại do Ủy ban công tác ngôn ngữ, văn tự quốc gia Trung Quốc ban hành gồm 7 nghìn chữ, Bảng chũ Hán thường dùng cũng gồm 3500 chữ. Để nhớ được 3500 chữ Hán thường dùng không phải là điều đơn giản, đặc biệt chữ Hán lại là loại văn tự hình vuông được cấu tạo nên từ các nét bút. Việc thiếu thừa nét, khác nét, thậm chí chỉ cần độ dài ngắn của nét khác nhau đã tạo ra các chữ khác nhau, hoặc tạo ra các chữ không có trong hệ thống. Chính vì vậy chữ Hán là một trong những khó khăn lớn nhất của người Việt Nam khi học tiếng Hán. Điều này đặt ra yêu cầu cao đối với việc dạy chữ Hán, mà cụ thể ở đây là yêu cầu đối với người dạy. Theo chúng tôi, người dạy phải có nhận thức đúng, có phương pháp hợp lý và phải cung cấp đầy đủ các kiến thức cũng như kỹ năng cần thiết liên quan đến chữ Hán và việc viết chữ Hán cho người học.

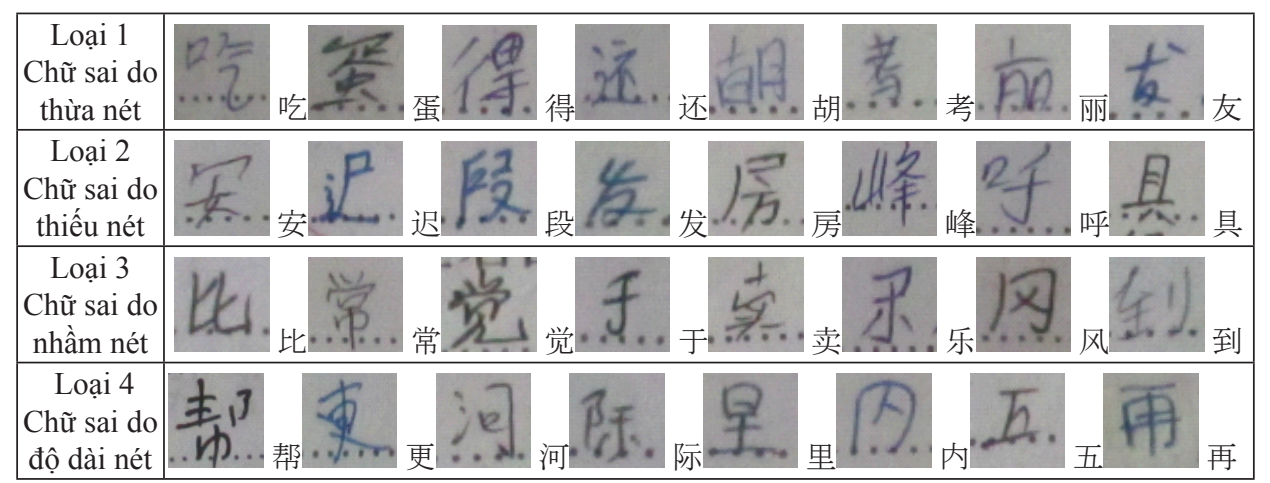


Về nhận thức: Nhận thức là vô cùng quan trọng, chỉ có nhận thức đúng thì mới có hành động đúng. Vì vậy, chúng tôi cho rằng trước tiên người dạy cần nhận thức rõ tầm quan trọng của chữ Hán và việc học chữ Hán. Nếu chỉ chú trọng đến nghe và nói thôi thì người học rất có thể sẽ giống như người mù chữ không đọc và viết được, hoặc đọc được nhưng không viết được hoặc viết kém. Điều này sẽ ảnh hưởng đến công việc sau này của người học.

Khi đã nhận thức được tầm quan trọng của chữ Hán thì việc giảng dạy chữ Hán phải được chú ý tiến hành trong suốt quá trình đào tạo và được quan tâm đúng mức trong tất cả các môn học. Hiện nay có xu hướng cho rằng việc dạy học và viết chữ Hán là nhiệm vụ của các môn thực hành tiếng ở giai đoạn cơ sở, với các môn lý thuyết tiếng ở giai đoạn cao chủ yếu học kiến thức chuyên ngành. Giáo viên lên lớp giảng chủ yếu sử dụng máy tính trình chiếu, cả buổi học có khi không viết chữ nào, hoặc có viết thì cũng rất hạn chế. Sinh viên chủ yếu đọc và học các bài giảng do giảng viên chuẩn bị sẵn, lên lớp không cần ghi chép. Chúng tôi cho rằng cách làm này là chưa thỏa đáng, ảnh hưởng nghiêm trọng đến khả năng viết chữ của sinh viên khi ra trường. Sử dụng công nghệ để nâng cao hiệu quả và chất lượng giảng dạy ngoại ngữ là điều tất yếu và nên làm song không nên quá lệ thuộc, với chữ Hán vẫn cần kết hợp cả viết và trình bày bảng để người học không quên chữ.

Người dạy cần nhận thức được những khó khăn của việc học chữ Hán, hiểu được thực trạng viết chữ Hán của người học từ đó đưa ra những giải pháp hữu hiệu. Ngoài ra, người dạy cũng cần giúp cho người học có nhận thức đúng về tầm quan trọng và những khó khăn của việc viết chữ Hán, nâng cao ý thức chủ động viết chữ, nhớ chữ của người học.
Về phương pháp: Có nhiều phương pháp giảng dạy chữ Hán và cũng có nhiều cách phân loại khác nhau. Ví dụ có thể dựa trên ba mặt hình, âm, ý của chữ Hán chia ra thành các phương pháp dạy hình thể, các phương pháp dạy âm đọc và các phương pháp dạy về ý nghĩa của chữ. Nếu chỉ căn cứ vào hình thể của chữ có thể chia ra thành các phương pháp dạy nét bút, phương pháp dạy bộ, phương pháp dạy chữ. Nếu căn cứ vào quá trình học chữ Hán có thể chia ra thành các phương pháp giới thiệu chữ Hán, các phương pháp giải thích chữ Hán (phân tích hình, âm, ý), các phương pháp kiểm tra viết chữ Hán.

Do chữ Hán khó học, khó nhận biết, khó nhớ nên người dạy cần linh hoạt sử dụng tổng hợp nhiều phương pháp để giúp người học nắm được âm đọc, hình thể và ý nghĩa của chữ. Trong ba mặt hình, âm, ý của chữ Hán cần đặc biệt chú ý sử dụng các phương pháp giúp người học ghi nhớ được hình thể của chữ. Các phương pháp cần lôi cuốn, gây chú ý, từ đó tạo say mê, hứng thú cho người học.

Ngay từ giai đoạn đầu, người dạy cần cung cấp các kiến thức liên quan đến bộ và giảng dạy chữ Hán thông qua việc phân tích các bộ trong chữ. Ví dụ khi dạy chữ nhân “人” cần cung cấp cho người học bộ nhân đứng “个 ” và nói rõ ý nghĩa của các chữ có bộ nhân đứng thường liên quan đến con người: 你 bạn, anh, chị (đại từ nhân xưng ngôi thứ 2 số ít); 他anh ấy, nó (đại từ nhân xưng ngôi thứ 3 số ít, chỉ người, con trai); 休nghỉ ngơi; 伙伴bạn bè; 住ở, sống ở; 伯 bác... Các chữ có bộ mộc “杨, 柳, 柿, 桃, 枫, 槐” thường chỉ các loài cây. Các chữ có bộ tài gảy “指, 拇; 把, 握, 拿, 扶, 推, 控, 打, 拾, 扔, 抽, 抄, 投, 抓, 拉, 押, 抱, 按, 撕, 挑, 捲, 揍, 抢, 拼, 搏, 搬, 接” thường chỉ các bộ phận hay động tác liên quan đến tay. Các chữ có bộ điểu "鸡, 鸦, 鸽, 鹏, 鹑, 鸥” thường liên quan đến chim 
chóc. Các chữ có bộ tâm (cả bộ tâm nằm và bộ tâm đứng) “惭, 愧, 恼, 恨, 愉, 快, 怖, 怯, 恐, 志, 恩, 思, 怨, 愁, 想, 悲” thường liên quan đến các hoạt động hay trạng thái tâm lý...

Đối với các chữ tượng hình, hội ý và một số chữ chỉ sự nên sử dụng phương pháp phân tích hình thể để nói rõ mối quan hệ giữa hình thể và ý nghĩa của chữ, cũng có thể thông qua cả tranh ảnh để chỉ ra sự biến đổi hình thể của chữ. Đây cũng chính là phương pháp nắm được ý nghĩa thông qua cấu tạo của chữ. Ví dụ khi dạy các chữ “贝vỏ sò, 册sách, 车xe, 水sông (nước), 鸟chim, 果quả” có thể đưa ra hình ảnh và diễn biến hình thể của chữ như dưới đây (Hình ảnh và biến đổi hình thể của chữ Hán chúng tôi tham khảo 李乐毅 1992, 1999):

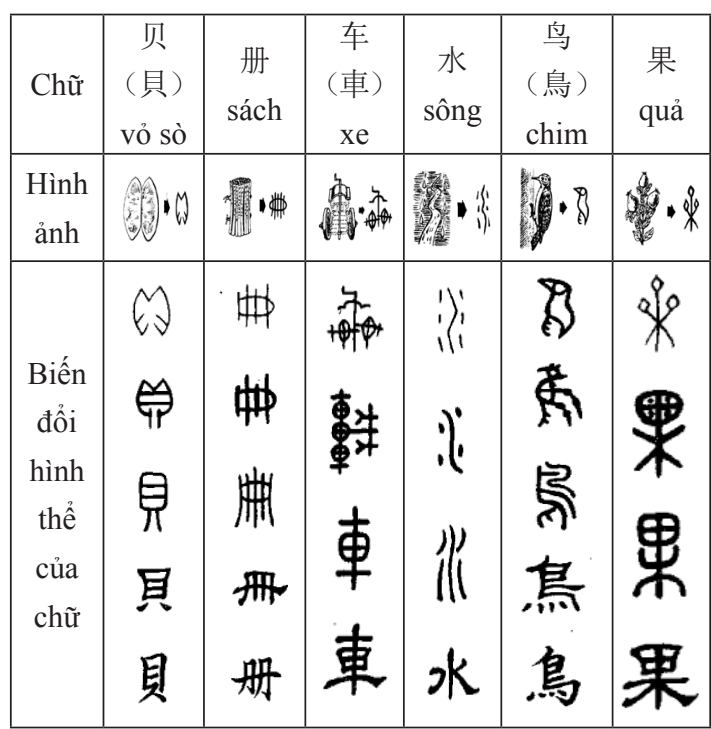

Đối với các chữ hình thanh cần sử dụng phương pháp phân tích hình thể của chữ, chỉ ra bộ phận biểu thị âm thanh (thanh phù) và bộ phận biểu thị ý nghĩa (hình phù) của chữ. Ví dụ các chữ “请, 清, 情, 晴, 睛, 蜻” đều là các chữ hình thanh, phần bên phải “青” biểu thị âm đọc, phần bên trái biểu thị ý nghĩa. “请” là "mời” nên có bộ ngôn“i ”, “清” là “trong” nên có bộ ba chấm thủy “シ̀ ”, “情” là “tình cảm” nên có bộ tâm đứng “小”, “晴” là “trời nắng” nên có bộ nhật “日”, “睛” là “mắt” nên có bộ mục“目”, “
蜻” là “con chuồn chuồn” nên có bộ trùng “虫”. Hay các chữ “抱, 饱, 鲍, 炮, 跑, 袍” cũng vậy, chúng đều là các chữ hình thanh, có “包” biểu thị âm đọc, phần còn lại biểu thị ý nghĩa, “抱” là “ôm” nên có bộ tài gảy “f”, “饱” là “no” nên có bộ thực “饥” “鲍” là “một loại cá” nên có bộ ngu “鱼”, “炮” là “pháo” nên có bộ hỏa “火”, “ 跑” là “chạy” nên có bộ túc “足 ”, “袍” là “một loại áo” nên có bộ y “衣”.

Nếu sử dụng phương pháp này chúng tôi cho rằng có thể giúp người học tránh được nhiều lỗi sai. Hãy xem ví dụ trong bảng dưới đây:

\begin{tabular}{|c|c|c|}
\hline Chữ sai & $\begin{array}{l}\text { Chữ } \\
\text { đúng }\end{array}$ & Phân tích \\
\hline & 初 & $\begin{array}{l}\text { Nếu biết rằng “初sơ" là chữ hội ý, do } \\
\text { bộ “衣y” và bộ “刀đao" cấu tạo nên và } \\
\text { vốn có nghĩa là "giai đoạn đầu của việc } \\
\text { may áo, cần cầm dao để chia mảnh vải } \\
\text { ra làm nhiều miếng", thì người học sẽ } \\
\text { không viết sai chữ này. }\end{array}$ \\
\hline & 福 & $\begin{array}{l}\text { Bộ “不thị” vốn là cái bàn thờ, vì vậy } \\
\text { các chữ có bộ này làm hình phù thường } \\
\text { biểu thị ý nghĩa liên quan đến thờ } \\
\text { cúng, cấu chúc, may mắn, cấm kỵ (祭, } \\
\text { 祀, 福, 禄, 祝) ․ Nếu hiểu được vậy } \\
\text { người học sẽ không viết sai chữ “福 } \\
\text { phúc” này. }\end{array}$ \\
\hline & 穿 & $\begin{array}{l}\text { Nếu biết rằng “穿xuyên” là chữ hội ý, do } \\
\text { bộ “穴huyệt" và bộ “牙nha (răng)" cấu } \\
\text { tạo nên, vốn có nghĩa là “con chuột dùng } \\
\text { răng đào lỗ xuyên qua", thì người học sẽ } \\
\text { không viết sai chữ “穿xuyên" này. }\end{array}$ \\
\hline & 爬 & $\begin{array}{l}\text { “爬” là chữ hình thanh, trong đó “爪 } \\
\text { trảo (tay)” biểu thị ý nghĩa ("trèo" phải } \\
\text { dùng tay). “瓜 qua” là một loại quả, đây } \\
\text { là chữ chỉ sự, nét thứ ba biểu thị quả } \\
\text { treo trên giàn. Nếu hiểu như vậy người } \\
\text { học sẽ không viết sai chữ “爬” này. }\end{array}$ \\
\hline
\end{tabular}

Chữ Hán rất khó học, ông cha ta trước đây khi học chữ Hán đã tạo ra nhiều câu thơ, câu ca dao để ghi nhớ. Những câu thơ, câu ca dao này mặc dù không chỉ ra được nguồn gốc và cấu tạo của chữ, song nó có thể giúp người học ghi nhớ cách viết chữ, ví dụ:

“Chim chích mà đậu cành tre (Y)

Thập (十) trên tứ (四) dưới nhất (一) đè chữ tâm (心).” (chữ đức德)

"Đất gì mà đất bùn ao (土) 
Ai cắm cây sào mà cắm chẳng ngay $(J)$ Con ai mà đứng ở đây (子)

Đứng thì chẳng đứng dựa tay vào sào." (chữ hiếu孝)

Hay câu thơ của Hồ Xuân Hương:

"Duyên thiên (天) chưa thấy nhô đầu dọc (夫)

Phận liễu (了) sao đà nảy nét ngang (子)."

Chúng tôi cho rằng những câu thơ, câu ca dao này ngoài việc giúp người học nhó được chữ Hán ra, còn tạo hứng thú cho người học. Vì vậy người dạy nên tích lũy một số câu và sử dụng hợp lý trong giai đoạn cơ sở.

Một điểm quan trọng trong phương pháp giảng dạy chữ Hán là người dạy cần lường trước được những lỗi sai người học có thể mắc phải, từ đó trong khi dạy cần chỉ ra, lưu ý người học giúp họ tránh viết sai viết nhầm. Bảng dưới đây là một số ví dụ cần lưu ý khi dạy các chữ dễ viết nhầm:

\begin{tabular}{|c|c|c|}
\hline $\begin{array}{c}\text { Nguyên } \\
\text { nhân }\end{array}$ & $\begin{array}{l}\text { Các chữ } \\
\text { dễ nhầm }\end{array}$ & Phân tích \\
\hline \multirow{2}{*}{$\begin{array}{c}\text { Hình thể } \\
\text { giống } \\
\text { nhau }\end{array}$} & 千干 & $\begin{array}{l}\text { “千, 干” là hai chữ có số nét giống } \\
\text { nhau (3 nét), hình thể giống nhau } \\
\text { nên rất dễ nhầm. Sự khác biệt của } \\
\text { chúng là nét đầu của chữ “千” là } \\
\text { nét phẩy, còn nét đầu của chữ “ } \\
\text { 干” là nét ngang. Khi dạy cần chỉ } \\
\text { ra sự khác biệt này để người học } \\
\text { không bị nhầm. } \\
\text { Sự khác biệt của hai chữ “外, 处” } \\
\text { là ở nét thứ 3. “外” có nét thứ } 3 \\
\text { là nét chấm, còn “处” là nét mác } \\
\text { (nét mác dài và bao trùm sang } \\
\text { phần bên phải). }\end{array}$ \\
\hline & $\begin{array}{l}\text { 已己巳 } \\
\text { 牛午 } \\
\text { 未末 } \\
\text { 土土 }\end{array}$ & $\begin{array}{l}\text { Các nhóm chữ này có hình thể } \\
\text { giống nhau, chúng chỉ khác nhau } \\
\text { một chút về độ dài ngắn của nét } \\
\text { bút. Khi dạy cần phân biệt chúng } \\
\text { với nhau để người học không bị } \\
\text { nhầm. Ví dụ khi dạy chữ "巳" } \\
\text { xuất hiện trong từ "巳经", người } \\
\text { dạy cần nói rõ nét thứ } 3 \text { cắt lên } \\
\text { trên nét thứ } 2 \text {, nhưng không chậ } \\
\text { vào nét thứ nhất. Nếu không viêt } \\
\text { cắt lên trên sẽ thành chữ "己", } \\
\text { nếu chạm vào nét thứ nhất sẽ } \\
\text { thành chữ "巳". }\end{array}$ \\
\hline
\end{tabular}

\begin{tabular}{|c|c|c|}
\hline $\begin{array}{c}\text { Âm đọc } \\
\text { giống } \\
\text { nhau }\end{array}$ & $\begin{array}{l}\text { 里理 } \\
\text { 公工 } \\
\text { 历厉 } \\
\text { 汽气 } \\
\text { 炼练 } \\
\text { 健建 }\end{array}$ & 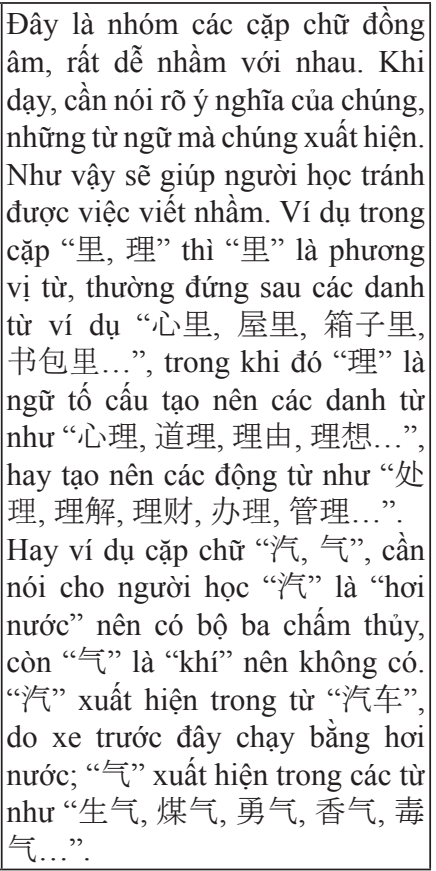 \\
\hline
\end{tabular}

Bảng dưới đây là một số ví dụ cần lưu ý khi dạy các chữ dễ viết sai:

\begin{tabular}{|c|c|}
\hline & Phân tích \\
\hline & $\begin{array}{l}\text { Khi dạy cần nói rõ cho người học } \\
\text { các chữ “真, 具, 填, 俱” đều có } \\
\text { ba nét ở bên trong, còn các chữ “ } \\
\text { 道, 首, 目” chỉ có hai nét. }\end{array}$ \\
\hline 2 & $\begin{array}{l}\text { Khi dạy cần nói rõ sự khác nhau ở } \\
\text { phần bên trên của các chữ “学, 觉”" } \\
\text { với các chữ “党, 当, 常, 堂, 尚, 赏, } \\
\text { 裳, 棠”. Phần bên trên của “学, 觉”" } \\
\text { là chấm, chấm và phẩy (các chữ } \\
\text { này thường có vận mẫu là üe hoặc } \\
\text { iao); còn phần bên trên của “党, 常, } \\
\text { 堂, 赏, 裳, 棠” là sổ giữa, chấm } \\
\text { bên trái và phẩy bên phải, các chữ } \\
\text { này thường có vận mẫu là “ang” do } \\
\text { có thanh phù là “尚”. }\end{array}$ \\
\hline & $\begin{array}{l}\text { Do ảnh hưởng của các chữ “戈, } \\
\text { 我, 钱, 成...” và “农, 衣, 裹...” } \\
\text { nên người học rất dễ̂ viết thừa nét } \\
\text { ở các chữ “试, 展”. Khi dạy để } \\
\text { ý chỉ ra sự khác biệt của chúng } \\
\text { để người học không viết thừa nét. }\end{array}$ \\
\hline & $\begin{array}{l}\text { Khi dạy cần nói rõ nét thứ } 2 \text { của } \\
\text { chữ "比” là nét ngang chứ không } \\
\text { phải phẩy, nét thứ hai của chữ “风" } \\
\text { là ngang xiên hất chứ không phải } \\
\text { ngang gập hất hay ngang gập uốn. }\end{array}$ \\
\hline$E$ Ex & $\begin{array}{l}\text { Khi dạy cần nói rõ nét mác của } \\
\text { “越, 题, 起...” ở bên trái cần } \\
\text { kéo dài và bao phủ được phần } \\
\text { bên trái. }\end{array}$ \\
\hline
\end{tabular}




\section{Về kiến thức và kỹ năng cần giảng}

dạy: Theo chúng tôi kiến thức và kỹ năng về việc viết chữ Hán cần được chia làm hai giai đoạn để giảng dạy, đó là giai đoạn cơ sở và giai đoạn nâng cao.

Ở giai đoạn cơ sở người dạy cần hướng dẫn cẩn thận, chi tiết để người học có được các kỹ năng cầm bút, đặt bút, dùng lực của tay khi viết. Các kiến thức cơ bản cần cung cấp cho người học như: 1 . Kiến thức về các nét bút, bao gồm các nét cơ bản và các nét ghép. Với 6 nét cơ bản như ngang, sổ, phẩy, chấm (chấm ngắn, chấm dài), mác và hất có thể giảng dạy ngay và yêu cầu người học tập viết. Với 25 nét ghép như ngang gập, ngang phẩy, ngang móc... có thể giới thiệu cho người học khi xuất hiện trong các chữ cụ thể. Khi đó cần nói rõ tên nét, cách viết, phân biệt với các nét đã học và yêu cầu người học tập viết; 2 . Kiến thức về bộ và các bộ, khi bộ xuất hiện ở các chữ trong bài, người dạy cần cung cấp tên gọi, ý nghĩa, cách viết cho người học; 3. Kiến thức về chữ viết, bao gồm cách viết, âm đọc, cấu tạo và ý nghĩa của chữ. Trong khi giảng dạy cần so sánh với các chữ đồng âm, cận âm, các chữ có hình thể gần giống nhau để người học tránh viết sai viết nhầm; 4. Các quy tắc viết chữ Hán, bao gồm các quy tắc cơ bản, các quy tắc bổ sung và các quy tắc nhường nét. Trong việc giảng dạy chữ Hán ở giai đoạn cơ sở hiện nay, người dạy mới chỉ chú ý cung cấp cho người học các quy tắc cơ bản, các quy tắc bổ sung và các quy tắc nhường nét chưa được chú ý đúng mức. Các quy tắc bổ sung xin xem 张静贤 (2004: 40), các quy tắc nhường nét xem 张 静贤 (2004: 35-37). Ngoài ra, người dạy cũng nên giới thiệu các phần mềm và các trang mạng hướng dẫn viết chữ Hán để người học tham khảo.

Ở giai đoạn cao, người dạy cần cung cấp cho người học những kiến thức về chữ Hán một cách hệ thống thông qua môn Văn tự học. Các kiến thức bao gồm lịch sử phát triển của chữ Hán, đặc điểm tính chất của chữ Hán, sự biến đổi hình thể của chữ Hán và đặc biệt là cấu tạo của chữ Hán theo "tứ thư" (tượng hình, chỉ sự, hội ý, hình thanh). Đối với các chữ hình thanh cần nói rõ tác dụng biểu âm của thanh phù và tác dụng biểu ý của hình phù. Không chỉ vậy, để người học nắm được hệ thống, người dạy nên chia các chữ Hán theo các mảng như các chữ liên quan đến con người, các chữ liên quan đến động vật, các chữ liên quan đến đồ vật, các chữ liên quan đến các hiện tượng tự nhiên... Ví dụ khi giảng dạy về các chữ Hán liên quan đến tay (một phần của các chữ Hán liên quan đến con người), chúng tôi cung cấp các chữ một cách hệ thống như sau:

手, 又, 爪đđều là “tay”; 友hai tay bắt lấy nhau nên có nghĩa là "bạn"; 有 tay cầm miếng thịt nên có nghĩa là “có"; 隻 (giản thể 只) tay bắt một con chim nên là lượng từ của "chim, gà...”; 雙 (giản thể 双) tay bắt hai con chim nên là lượng từ có nghĩa là "đôi”; 受 tay cầm một vật đưa cho cái tay khác nên có nghĩa là “đưa" và "nhận"; 爱 (bây giờ dùng 援) tay cầm cái que cứu cái tay khác ở dưới nước nên giờ có nghĩa "viện trợ"; 取trong chiến trận, sau khi giết được kẻ địch, dùng tay cắt lấy tai trái mang về để tính công nên có nghĩa là "lấy"; 看lấy tay che mắt để nhìn xa, nhìn rõ nên có nghĩa là "nhìn"; 奴 tay bắt người con gái mang về nhà làm "nô lệ"; 采tay hái cây nên có nghĩa là "hái"; 付 tay cầm một vật trả cho người khác nên có nghĩa là "trả"; 及 tay bắt lấy người khác nên có nghĩa là "bắt kịp"; 孚 (bây giờ dùng 俘) tay bắt lấy đứa trẻ mang về nên có nghĩa là "con tin"; 鬥 (giản thể 斗) hai tay cầm gậy đánh nhau nên có nghĩa là “đấu”; 鬧 (giản thể 闹) hai tay cầm gậy đánh nhau ở giữa chợ (市) nên có nghĩa "ồn ào"; 君tay cầm quyền trượng, miệng ra lệnh nên có nghĩa là "vua"; 牧tay cầm gậy đuổi trâu bò đi chăn nên có nghĩa "chăn trâu, bò"; 冠 tay cầm mũ đội lên đầu nên có nghĩa là "mũ"; 戒hai tay cầm vũ khí trong tay nên có nghĩa 
là "cảnh giác, cảnh giới”. Ngoài ra, chúng tôi cũng cung cấp các chữ liên quan đến tay để người học tìm hiểu như: 娶, 左, 右, 肱, 寸, 封, 射, 放, 把, 握, 扶, 拿, 尹, 推, 控, 打, 拾, 扔, 抽, 抄, 投, 抓, 拉, 押, 抱, 按, 撕, 挑, 捲, 揍, 拼, 搏, 搬, 接, 攻, 政, 改, 放, 效, 救, 敲, 掌, 拳, 指, 拇, 弃, 典, 败, 教, 完, 弄, 兵 $\cdots$

\section{2. Đối với việc học chũ Hán}

Người học cần nhận thức rõ tầm quan trọng của việc viết chữ Hán cũng như ý thức được rằng chữ Hán là một trong những khó khăn lớn nhất khi học tiếng Hán. Đồng thời, cần có ý thức chủ động trong việc viết chữ và nhớ chữ.

Đối với người học, giai đoạn cơ sở là vô cùng quan trọng. Đây là giai đoạn học tập những kiến thức và kỹ năng căn bản để định hình cho chữ viết và việc viết chữ sau này. Người học cần đi học đầy đủ, chú ý nghe giảng. Sau mỗi bài học, mỗi chữ cần dùng bút chì viết nhiều lần vào giấy ô ly, trước khi viết cần quan sát kỹ các nét bút, độ dài ngắn của các nét, các bộ, kết cấu chữ... Sau khi viết cần đối chiếu kiểm tra lại chữ viết của mình với chữ viết trong sách xem đúng chưa, đẹp chưa. Cần đặt yêu cầu là viết đẹp chứ không chỉ dừng lại ở việc nhớ và viết đúng chữ. Hiện tại, do chương trình khá nặng, nên cả người dạy và người học đều chỉ chú ý đến việc chạy theo chương trình, dạy và học cho xong chứ chưa quan tâm đúng mức đến việc viết chữ, có chăng cũng chỉ cần viết đúng là được, hệ quả là chữ viết nói chung còn chưa được đẹp.

Ở giai đoạn cao hơn khi chữ viết đã định hình, người học có thể chỉ chú ý nhiều hơn đến việc viết để nhớ chữ, song mỗi ngày cũng nên dùng khoảng 20 đến 30 phút để luyện viết chữ đẹp. Khi viết cần lưu ý chữ đồng âm, cận âm và các chữ có hình dạng giống nhau để tránh viết sai viết nhầm. Ở giai đoạn học các môn lý thuyết sau này, mặc dù không còn yêu cầu của người dạy song người học cần định kỳ 3 đến 4 tuần ôn lại các chữ đã học, trong quá trình học cần thường xuyên ghi chép bằng chữ Hán để tránh quên chữ.

\section{3. Đối với các công tác khác}

Do viết chữ là một trong những khó khăn lớn nhất của người học khi học tiếng Hán, vì vậy ngoài dạy và học ra, các công tác khác cũng phải tiến hành đồng bộ. Khi xây dựng chương trình cần có các môn học để nâng cao khả năng viết chữ, nhớ chữ của người học (ví dụ môn Văn tự học). Khi biên soạn giáo trình, đặc biệt là các giáo trình ở giai đoạn cơ sở cần chú ý đúng mức đến việc cung cấp các kiến thức và kỹ năng về chữ viết và việc viết chữ cho người học. Tốt nhất trong mỗi bộ giáo trình cần có giáo trình bổ trợ chuyên về việc luyện viết chữ Hán.

Công tác kiểm tra đánh giá cũng vô cùng quan trọng. Người dạy phải có ý thức giao bài tập và kiểm tra bài tập liên quan đến việc viết chữ của người học, đặc biệt là ở giai đoạn cơ sở. Khi kiểm tra cần nhận xét, chỉnh sửa và cho điểm (có thể tính làm một phần điểm chuyên cần) để người học có ý thức hơn. Đối với các môn thi viết cần dành riêng một phần điểm thưởng cho việc viết đúng và viết đẹp, có thể là 0,3 đến 0,5 điểm. Ngược lại, nếu viết sai, viết nhầm sẽ bị trừ điểm, ví dụ 3 lỗi viết sai viết nhầm bị trừ 0,1 điểm.

Các hoạt động ngoại khóa, các trò chơi đố chữ, viết chữ, ghép chữ, tìm chữ nên được thường xuyên tổ chức ở phạm vi của lớp, của khóa, của khoa. Nên định kỳ tổ chức các lớp thư pháp bút máy để người học tham gia. Tất cả những hoạt động này sẽ giúp cho người học ý thức được tầm quan trọng của việc viết chữ, từ đó có thể nâng cao chất lượng chữ viết, giúp người học có thể viết đúng, viết đẹp. 


\section{Kết luận}

Chữ Hán là một trong những khó khăn lớn nhất của sinh viên Việt Nam khi học tiếng Hán. Hiện tượng viết sai, viết nhầm diễn ra rất phổ biến. Trong 150 bài thi tốt nghiệp môn viết của sinh viên khóa QH 2011, Khoa Ngôn ngữ và Văn hóa Trung Quốc, Trường Đại học Ngoại ngũ̃, ĐHQGHN, chúng tôi thống kê có 1147 chữ có vấn đề, trung bình mỗi bài thi có 7,65 chữ. Nếu xét theo lượt chữ thì có tổng cộng 3141 lượt chữ có vấn đề, trung bình mỗi bài có 20,94 lượt. “已, 觉, 学, 河, 里, 展, 幸, 真, 城, 试, 题, 污” là những chữ có số bài viết có vấn đề nhiều nhất. Nếu xét theo số lượt thì “河, 觉, 学, 已, 幸, 那, 越, 城, 展, 试” là 10 chữ có lượt lỗi sai nhiều nhất.

Bài viết đã tiến hành phân loại các chũ viết có vấn đề thành chữ không viết được, chữ viết phiên âm, viết nhầm và chữ viết sai. Nếu nhìn vào số lượng chữ thì số chữ viết nhầm nhiều nhất, tổng cộng 502 chữ, chiếm 43,77\% tổng số chữ có vấn đề, song nếu căn cứ vào số lượt thì chữ viết sai lại đứng đầu với 1649 lượt, chiếm $52,5 \%$ tổng số lượt các chữ có vấn đề. Đối với các chữ viết nhầm và chữ viết sai, bài viết tiếp tục tiến hành phân loại chi tiết hơn.
Trên cơ sở thống kê, phân loại, bài viết đưa ra những kiến nghị đối với việc dạy và học chữ Hán. Trước tiên người dạy và người học cần nhận thức rõ tầm quan trọng của chữ Hán, việc học chữ Hán cũng như những khó khăn trong việc viết chữ. Về phương pháp, người dạy cần linh hoạt sử dụng tổng hợp nhiều phương pháp để giúp người học nắm được âm đọc, hình thể và ý nghĩa của chữ, trong đó cần đặc biệt chú ý sử dụng các phương pháp giúp người học ghi nhớ được hình thể của chữ. Việc giảng dạy cần cung cấp đầy đủ các kiến thức và kỹ năng về chữ Hán và việc viết chữ Hán cho người học. Người học cần chủ động, tích cực và dành thời gian để viết đúng viết đẹp chữ Hán. Để nâng cao chất lượng chữ viết cho người học, các công tác xây dựng khung chương trình, biên soạn giáo trình, các hoạt động kiểm tra đánh giả, hoạt động ngoại khóa cần được tiến hành đồng bộ.

\section{Tài liệu tham khảo}

张静贤 (2004). 汉字教程 [M]. 北京: 北京语言大 学出版社.

李乐毅 (1992). 汉字演变五百例 [M]. 北京: 北京 语言学院出版社.

李乐毅 (1999). 汉字演变五百例续编 [M]. 北京： 北京语言文化大学出版社.

\section{THE SURVEY RESULTS OF CHINESE CHARACTERS WRITING BY VIETNAMESE STUDENTS Nguyen Dinh Hien}

\section{Faculty of Chinese Language and Culture, VNU University of Languages and International Studies, Pham Van Dong, Cau Giay, Hanoi, Vietnam}

Abstract: Writing Chinese characters is one of the biggest difficulties of Vietnamese students while learning Chinese. The phenomenon of writing wrong is very popular, but successful research on this is still limited. The research focused on Chinese characters written wrong or mistaken by Vietnamese students on the basis of the 150 final exams by QH 2011 students from the Faculty of Chinese Linguistics and Culture, VNU University of Languages and International Studies. Moreover, the research pointed out the reasons for this phenomenon and gave some suggestions to improve it.

Keywords: characters, Chinese characters, Chinese characters written wrong and mistaken 